\title{
Human Anti-Mouse Antibodies Negative
}

National Cancer Institute

\section{Source}

National Cancer Institute. Human Anti-Mouse Antibodies Negative. NCI Thesaurus. Code C128838.

Indicates that human anti-mouse antibodies have not been detected in a sample. 